\title{
Polyclonal cytomegalovirus-specific antibodies not only prevent virus dissemination from the portal of entry but also inhibit focal virus spread within target tissues
}

\author{
Nikolaus Wirtz $\cdot$ Sina I. Schader · Rafaela Holtappels • \\ Christian O. Simon • Niels A. W. Lemmermann • \\ Matthias J. Reddehase · Jürgen Podlech
}

Received: 7 March 2008 / Published online: 26 March 2008

(C) Springer-Verlag 2008

\begin{abstract}
Therapy of cytomegalovirus (CMV) infection in recipients of hematopoietic stem cell transplantation (HSCT) by immune serum transfer did not fulfill the high clinical expectations, although immune sera or immunoglobulin-enriched preparations pooled from many CMVimmune donors are likely to contain virus neutralizing antibodies covering a broad range of virus variants. Likewise, the highest risk of CMV disease in HSCT recipients results from the reactivation of the latently infected recipient's own virus despite pre-transplantation humoral immunity. These findings suggest the conclusion that antiviral antibodies are inefficient in controlling CMV. Rather than B cells and antibodies, T cells, in particular CD8 T cells, are thought to play a major role in resolving established organ infection. In theory, antibodies, though being capable of neutralizing free virions, could fail to prevent cell-bound virus dissemination from the portal of entry to distant target tissues and also could fail in preventing cell-to-cell spread within tissue. Here we have used murine model systems, including B cell deficient C57BL/6 $\mu^{-} \mu^{-}$( $\left.\mu \mathrm{MT}\right)$ mutants, to revisit the role of antiviral antibodies in the control of CMV infection and to reevaluate the prospects of an antibody-based immunotherapy from a basic science point of view.
\end{abstract}

Keywords Antiserum - Antiviral antibodies $\cdot$ B cells . B-cell deficient mouse mutant · Cytomegalovirus .

N. Wirtz $\cdot$ S. I. Schader $\cdot$ R. Holtappels $\cdot$ C. O. Simon

N. A. W. Lemmermann · M. J. Reddehase · J. Podlech ( $\square)$

Institute for Virology, Johannes Gutenberg-University,

Obere Zahlbacher Strasse 67, Hochhaus am Augustusplatz,

55131 Mainz, Germany

e-mail: podlech@uni-mainz.de
Hematopoietic stem cell transplantation (HSCT) · Immunotherapy $\cdot$ Immunodominant epitope $\cdot$ Serum transfer · Virus cell-to-cell spread · Virus dissemination . Virus latency $\cdot$ Virus reactivation

\section{Introduction: clinical background and murine models}

The role of antiviral antibodies in the control of cytomegalovirus (CMV) infection is a matter of discussion (for a more recent review, see [1]). In hematopoietic stem cell transplantation (HSCT), prevention of CMV infection and disease by intravenous transfer of immmunoglobulins (IVIG) derived from pools of CMV-immune serum donors were, on balance, underperforming and failed to replace other therapy options. Likewise, vaccines based solely on the induction of an antibody response are likely to fall short in providing full protection, so that current vaccination approaches are aimed at inducing both humoral and cellular adaptive immunity (for an overview, see [2-5]).

From a clinical risk assessment, it became clear that under the conditions of HSCT a pre-transplantation humoral immunity of the recipients fails in protecting against reactivation of latent $\mathrm{CMV}$ and consequent recurrent infection and disease; yet, this may relate in part to a gradual decline in antibody titers after the immunodepleting hematoablative conditioning due to the half life of antibodies in the absence of new production. As discussed in greater detail by Seckert et al. in this issue of MMI, the donor (D) and recipient (R) serostatus defines the risk of CMV reactivation after $\mathrm{HSCT}$ with a risk ranking of $\mathrm{D}^{-} \mathrm{R}^{+}>\mathrm{D}^{+} \mathrm{R}^{+}>\mathrm{D}^{+} \mathrm{R}^{-}$[6]. The lower risk in a $\mathrm{D}^{+} \mathrm{R}^{+}$as compared to a $\mathrm{D}^{-} \mathrm{R}^{+}$combination has been ascribed to the transfer of donor immune cells, of CMV-specific memory CD8 $\mathrm{T}$ cells in particular, whereas the recipient's own 
residual immunity cannot cope with virus reactivation in organs.

Many parameters in clinical protocols might obscure a role for antibodies in controlling human CMV (hCMV), whereas the murine model allows systematic experimental approaches, including elegant genetic approaches manipulating both the virus and the host (see the contributions by Sacher et al. and by Waisman et al., respectively, in this issue of MMI). Early studies by Araullo-Cruz et al. [7] followed by Shanley et al. [8] have shown that immune serum obtained from mice infected with murine cytomegalovirus (mCMV), when passively transferred, can protect recipient mice from lethal infection with the homologous virus. As a correlate for the clinical situation of infection with multiple virus variants, Gorman et al. [9] have documented successive infection by a naturally occurring recent mCMV isolate and the mCMV laboratory strain K181, suggesting that neither antibodies nor cellular immunity can completely block reinfection of primed mice with a heterologous virus. Passive transfer of immune serum, however, failed in preventing the establishment of viral latency [8] and it also failed in preventing all manifestations of CMV disease, with experimental retinitis being a noted example [10].

A host genetics approach using the B-cell deficient C57BL/6 $\mu^{-} \mu^{-}$mouse strain, which was generated by targeted disruption of a membrane exon of the $\mathrm{Ig} \mu$ chain gene ( $\mu \mathrm{MT}$ mutant) [11] and backcrossing to C57BL/6, showed that $\mathrm{B}$ cells, and thus also antibodies, are dispensable for resolving acute mCMV infection and cannot prevent virus reactivation from latency. Antibodies were, however, critically involved in limiting the dissemination of reactivated virus thus keeping recurrent infection local [12, 13]. As shown elegantly by Klenovsek et al. [14], adoptive transfer of memory B cells derived from mCMV-primed C57BL/6 donors reduced virus multiplication and durably protected against lethal CMV disease in otherwise immunodeficient homozygous $\mathrm{RAG}^{-1-}$ mutant mice. Notably, in that study, virus-specific memory B cells not only showed a prophylactic potential but also were effective even when administered therapeutically at an early stage of established infection, on day 3 in the specific case documented. Protection by memory B cells was most likely mediated by antibodies, as antiviral function coincided with the appearance of newly produced antibodies and because transfer of immune serum protected with no delay, though only transiently [14].

On the histopathogenetic level, it remained open to question if the main function of antibodies is to inhibit virus dissemination from the portal of entry to target tissues as well as the formation of secondary foci within target tissues or if antibody can even inhibit the cell-to-cell spread of virus that is required for the formation of more extended primary foci. This specific question is addressed here.

\section{Results}

A positive CMV immune status inhibits CD8 T cell priming at a peripheral portal of virus entry

In our experience, it is essentially impossible to superinfect a CMV-immune mouse with the homologous virus, at least when the system is not overwhelmed by unreasonably high virus doses and when the route of infection does not avoid the draining lymph node. Our experiments refer to subcutaneous, intraplantar infection, a route for which the popliteal lymph node is the draining lymph node, and to the moderate infection dose of $10^{5} \mathrm{PFU}$ of cell culture propagated mCMV-WT.Smith, if not indicated otherwise. Protection against infection was likely mediated by a serum component, as combined hematoablative treatment by a 7 Gy total-body $\gamma$-irradiation and depletion of CD4- and CD8 T cells as well as of natural killer (NK) cells did not annul the blockade (unpublished observation). Under no circumstances could dissemination to distant organs, such as the liver, be detected by IE1-protein specific immunohistology or by the virus plaque forming unit (PFU) assay (data not shown).

A highly sensitive indicator for viral gene expression is the priming of CD8 T cells specific for epitopes of viral proteins that are not present in virions, such as the immediate-early phase protein IE1 (pp76/89) and the early phase protein m164 (gp36.5) [15-17]. We know that 10 PFU can prime CD8 $\mathrm{T}$ cells in immunocompetent BALB/c mice (Verena Böhm, manuscript in preparation). The advantage over the detection of viral transcripts or proteins is that primed CD8 $\mathrm{T}$ cells are maintained after resolution of the acute infection and can, therefore, testify also a transient and past infection.

As shown in Fig. 1 (top panel), infection of immunocompetent, CMV-naïve BALB/c mice leads to high frequencies of $\mathrm{CD} 8 \mathrm{~T}$ cells specific for $\mathrm{L}^{\mathrm{d}}$-restricted IE1 peptide and $\mathrm{D}^{\mathrm{d}}$-restricted $\mathrm{m} 164$ peptide-the two currently known immunodominant peptides in the $H-2^{d}$ haplotype $[15,16,18]$ (see also the review article by Holtappels et al. in this issue of MMI) - in the popliteal lymph node at 1 week after infection. For a qualitative assessment of a $\mathrm{CD} 8 \mathrm{~T}$ cell response to superinfection in CMV-immune mice, instead of measuring an elevated recall response, it is advantageous to use marker epitopes for which CMVimmune mice were not primed, so that one can measure a primary response to these particular epitopes in spite of previous virus encounter. With this rationale, the first infection was performed with recombinant virus mCMV- $\triangle \mathrm{IDE}$, in which the two immunodominant epitopes (IDEs) IE1 and m164 are functionally deleted by replacing their respective C-terminal MHC anchor residues with alanine, that is by mutations L176A and $\mathrm{I} 265 \mathrm{~A}$, respectively (Holtappels 
mCMV-WT.BAC

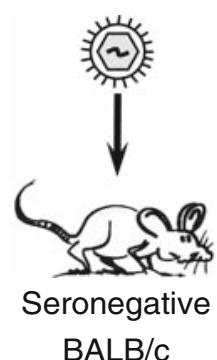

$\mathrm{BALB} / \mathrm{c}$

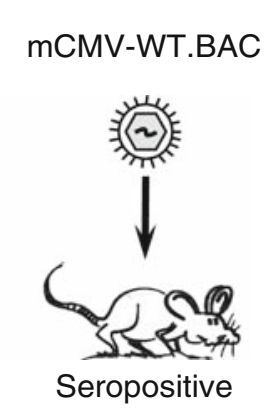

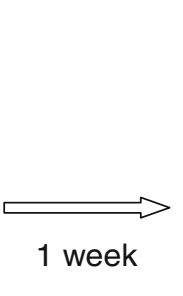

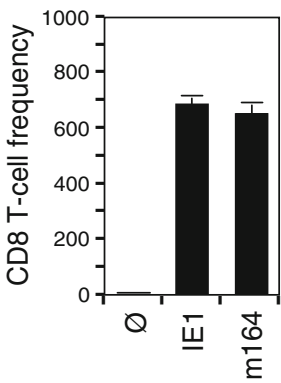

Peptides

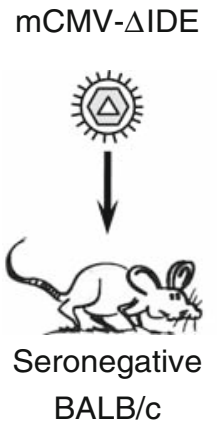

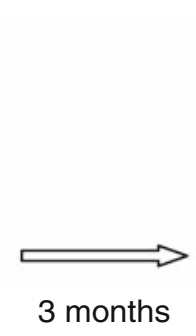

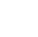
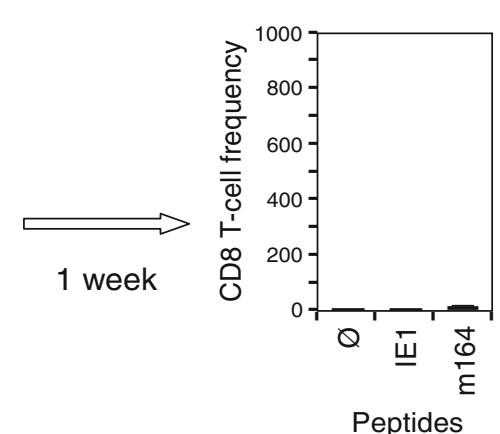

Fig. 1 Influence of CMV serostatus on CD8 T-cell priming. (top panel) Primary CD8 T-cell response in the draining popliteal lymph node of immunocompetent BALB/c mice at one week after intraplantar infection with $10^{5} \mathrm{PFU}$ of mCMV-WT.BAC. Frequencies of IE1 and m164 epitope-specific cells among immunomagnetically purified CD8 $\mathrm{T}$ cells were determined by an enzyme-linked immunospot (ELISpot) assay based on the epitope-stimulated secretion of interferon- $\gamma$. Stimulator cells in the assay were P815 $\left(H-2^{d}\right)$ mastocytoma cells exogenously loaded with synthetic peptides at optimal concentrations. Black

et al., manuscript in revision; for the mutagenesis rationale, see also the contribution by Böhm et al. in this issue of MMI). After 3 months, when immunological memory was established except for the two IDEs, challenge infection was performed with mCMV-WT.BAC, and the primary CD8 T-cell response to the IDEs was measured (Fig. 1, bottom panel). This highly sensitive assay for superinfection indeed detected some IDE-specific priming, but the frequencies of primed CD8 T cells were very low.

We concluded from this experiment that immune serum is highly effective in blocking infection already at the portal of virus entry.

Experimental regimen for a therapy of CMV infection by immune serum transfer

We next addressed the question if CMV-immune serum, in addition to inhibiting virus dissemination from the portal of entry to target tissues, can block cell-to-cell spread of virus bars represent the frequencies per $10^{5} \mathrm{CD} 8 \mathrm{~T}$ cells, error bars represent the upper $95 \%$ confidence limit determined by intercept-free linear regression analysis. $\varnothing$, no peptide added. (bottom panel) Analogous analysis of the primary CD8 T-cell response against the immunodominant epitopes (IDEs) IE1 and $\mathrm{m} 164$, but with $\mathrm{BALB} / \mathrm{c}$ mice that were infected with mutant virus mCMV- $\triangle \mathrm{IDE} 3$ months prior to challenge infection with mCMV-WT.BAC. See text for further explanation of the conception

within tissue or whether it rather inhibits the seeding of released progeny virus for secondary focus formation. The schema in Fig. 2 illustrates the study design for adoptive transfer of immune serum as an immunotherapy of CMV infection (for a similar strategy in CD8 T cell immunotherapy, see the review article by Holtappels et al. in this issue of MMI).

Immune serum donors were mice at 3 months after infection with mCMV-WT.Smith. Serum from uninfected, age-matched mice served to control for putative antibodyindependent serum effects (Fig. 2a). In a first set of experiments, serum donors were immunocompetent BALB/c mice, in a second set of experiments serum donors were C57BL/6 mice that were either heterozygous or homozygous for a targeted disruption of the Ig heavy-chain $\mu$ gene. These donors were thus immunocompetent or B-cell deficient, respectively. As expected, virus neutralizing activity was found only in sera from infected BALB/c and C57BL/ $6 \mu^{+} \mu^{-}$mice (Fig. 3). 
Fig. 2 Experimental regimen for a therapy of CMV disease by immune serum transfer. a Serum donors, BALB/c mice or heterozygous and homozygous Ig $\mu$-chain mutants of C57BL/6 were primed by intraplantar infection with $10^{5} \mathrm{PFU}$ of mCMV-WT.Smith, 3 months prior to serum donation. Age-matched uninfected mice of the same strains provided nonimmune control sera. b Serum transfer recipients were $\mathrm{BALB} / \mathrm{c}$ mice immunocompromised by total-body $\gamma$-irradiation with a single dose of $6.5 \mathrm{~Gy}$ (flash sym$b o l)$ and infected in the left hind footpad ( $s c$ intraplantar subcutaneous infection) with $10^{5} \mathrm{PFU}$ of mCMV-WT.Smith. Intravenous transfer of $500 \mu \mathrm{l}$ of serum (antibody symbol) was performed on day 6 , a time when the infection is established in host tissues. Days of analysis are indicated
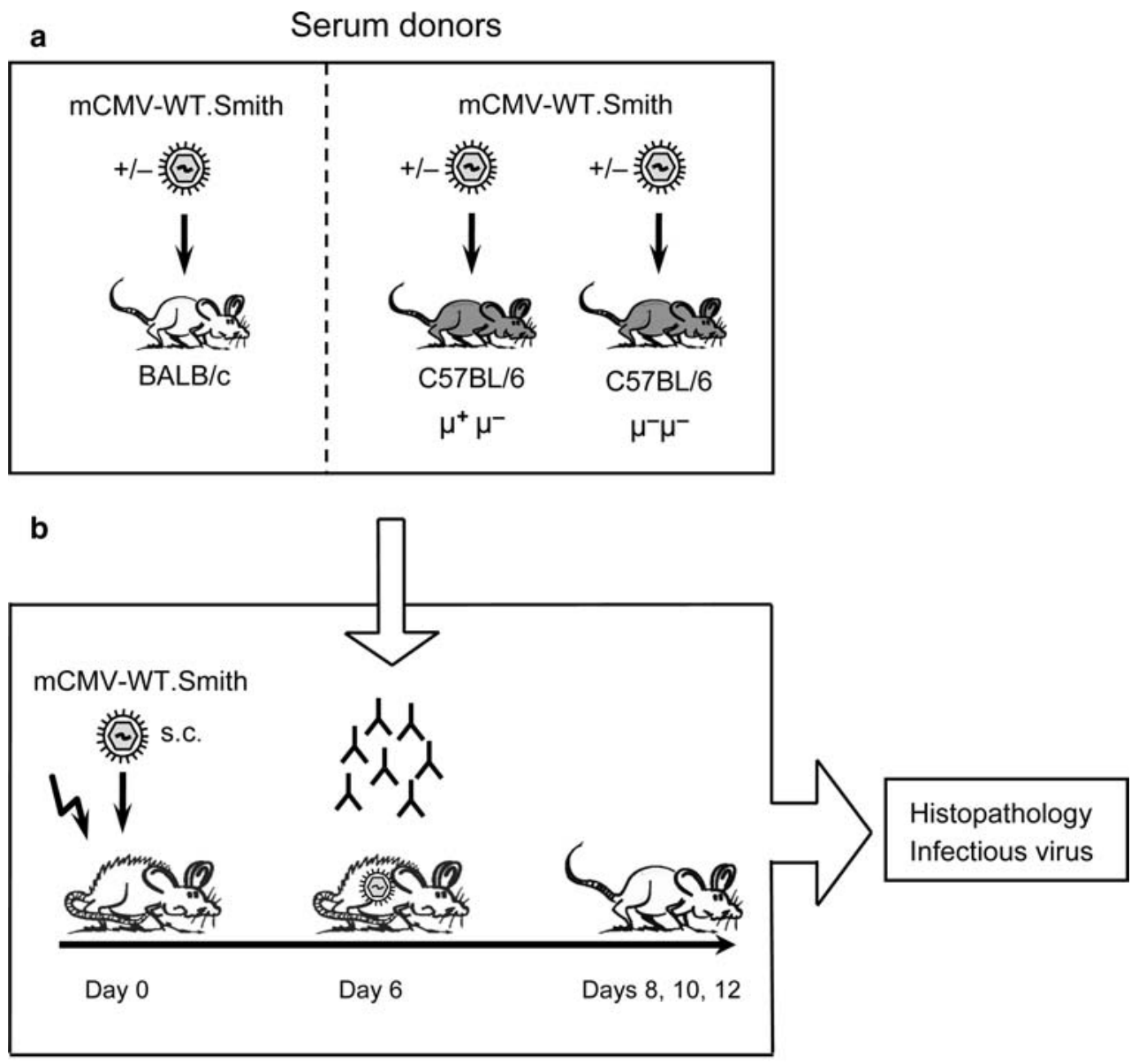

Serum transfer recipients

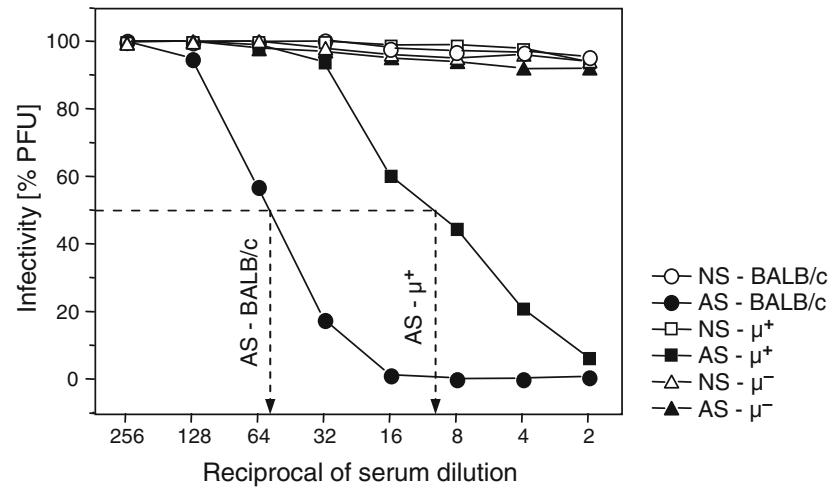

Fig. 3 Virus neutralizing capacity of donor sera. Standard neutralization assay (without exogenous complement) performed for mCMVWT.Smith with the sera indicated by different symbols (see internal symbol legend). Closed and open symbols indicate mCMV-primed and unprimed serum donors, respectively. NS normal (non-immune) serum. AS antiserum. Dashed lines indicate the serum dilutions at which a $50 \%$ plaque reduction was reached

Serum recipients were BALB/c mice that were immunocompromised by total-body $\gamma$-irradiation and infected with mCMV-WT.Smith (Fig. 2b). As shown previously by Erlach et al. [19] for equivalent experimental conditions, infected cells become detectable in liver tissue by IE1 protein specific immunohistology at $\sim$ day 4 after infection (95\% confidence interval: $2.5-4.5$ days), which is in good accordance with the time course of infection with luciferase reporter virus mCMV157luc in combined $\mathrm{T}$-and $\mathrm{B}$-cell immunodeficient $\mathrm{RAG}^{-/-}$mice detected by longitudinal bioluminescence imaging [14]. Serum transfer on day 6 thus has to cope with an already established tissue infection, though still at an early stage prior to clinical symptoms of disease.

Immune serum therapy of established tissue infection limits virus cell-to-cell spread

The key purpose of this study was to decide whether antibodies can only interfere with the founding of secondary infectious foci, which requires virus transit through extracellular tissue compartments that are thought to be easily accessible to antibodies, or whether antibodies also inhibit the growth of a primary infectious focus. The answer is given by an immunohistological study of the time course of infectious focus development in the liver (Fig. 4). 
Infected liver cells, which are mostly hepatocytes but also some endothelial cells and Kupffer cells, are identified by immunohistological staining of intranuclear IE1 protein in liver tissue sections (for methods, see [20]). On day 6, the time of serum transfer, single infected cells were detectable, which verified that virus had disseminated to the liver but was still in the first round of replication. In absence of CMV-specific adoptive immunity, that is after the transfer of BALB/c normal serum, infectious foci were found to expand steadily in a centrifugal direction until on day 12 three-dimensional plaque-like lesions were formed with diameters of $\sim 250 \mu \mathrm{m}$ and characterized by a center with lysed cells surrounded by a rim of more recently infected cells (Fig. 4, upper row) [16]. As we know from previous work, this focus expansion in the liver corresponds to a loglinear growth curve with a doubling time of the number of infected cells of $\sim 18 \mathrm{~h}$ [21]. This infectious focus development was completely inhibited by the transfer of immune serum (Fig. 4, lower row), though infected single cells and little groups of cells remained present.

Antiviral antibodies are the protective principle in CMV-immune serum

From all the said and shown, it is obvious that antibodies are the most likely candidates for the underlying protective principle in immune serum, but a formal scientific proof must exclude an antiviral function of cytokines or other factors that might be induced by infection and thus might be present in immune serum but not in normal serum. In the experiment shown in Fig. 5, we, therefore, compared the antiviral function of all six sera that were explained in the schema of Fig. 2 and characterized for their virus neutralizing capacity in Fig. 3. Regardless of whether the read-out of the antiviral function was the number of liver cells expressing IE1 protein (Fig. 5a), the number of liver cells positive for viral DNA detected by in situ hybridization (Fig. 5b) [20, 22] or the amount of infectious virus (Fig. 5c), significant protection was only observed with the two sera that also contained virus neutralizing antibodies, that is with the immune sera from BALB/c and C57BL/ $6 \mu^{+} \mu^{-}$serum donors. In addition, the higher virus neutralizing activity of the BALB/c-derived immune serum (recall Fig. 3) corresponded to a higher antiviral activity in serum transfer recipients. Most importantly, immune serum from infected but B-cell deficient homozygous C57BL/6 $\mu^{-} \mu^{-}$ mutants did not protect at all when compared with the corresponding normal serum $(P$ values of $0.40,0.62$, and 0.86 for Fig. 5a-c, respectively). In contrast, the protection observed with immune serum from infected but B-cell intact heterozygous C57BL $/ 6 \mu^{+} \mu^{-}$mutants was significant when compared with its homozygous mutant counterpart ( $P$ values of $0.04,0.025$, and 0.015 for Fig. 5a-c, respectively). In conclusion, the protective antiviral activity of immune serum derived from infected C57BL/6 $\mu^{+} \mu^{-}$mice can be attributed to CMV-specific antibodies.

\section{Concluding remarks}

In full accordance with previous own data [12] and with the results obtained by Jonjić et al. [13] and, more recently, by

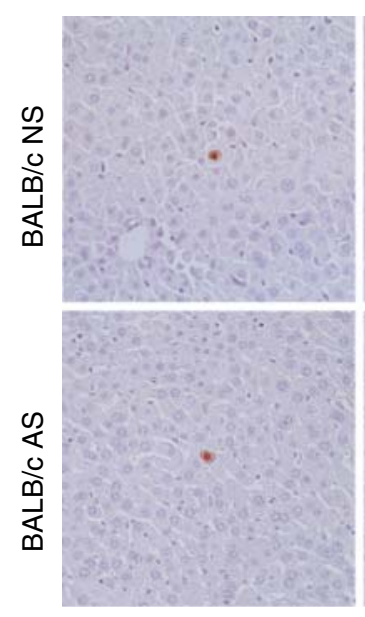

d6

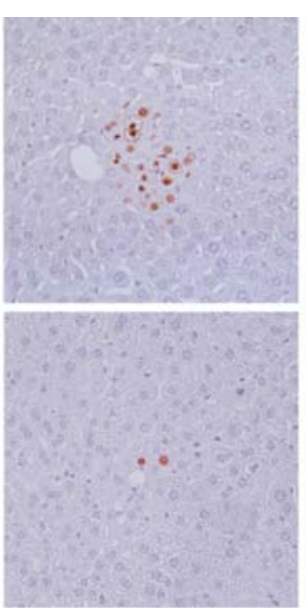

d8

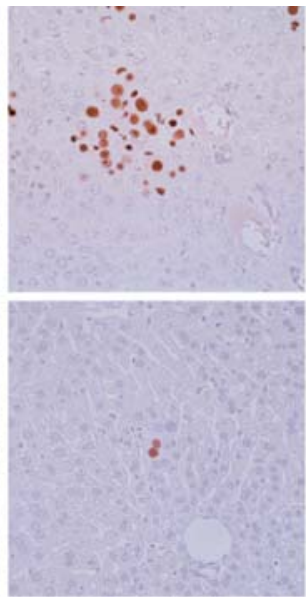

d10

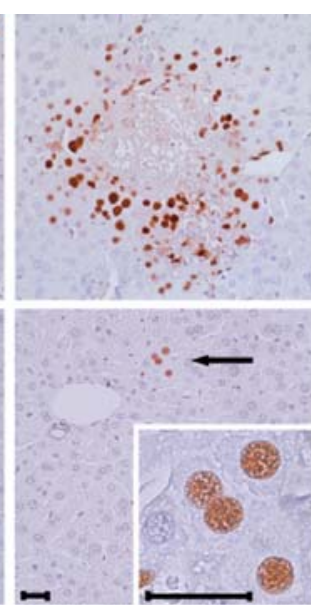

d12
Fig. 4 Immunohistological time course analysis of infectious foci development. Infected cells in liver tissue sections derived from serum transfer recipients at the time points indicated were detected by immunohistological brown staining of the intranuclear IE1 protein with monoclonal antibody CROMA 101 (S. Jonjić, Rijeka, Croatia) using the $\mathrm{ABC}$-peroxidase/DAB method. Light counterstaining was per- formed with haematoxylin (for methods, see [20]). Photographs represent a liver tissue section area of $0.1 \mathrm{~mm}^{2}$, bars represent $25 \mu \mathrm{m}$. The arrow points to a small infectious focus that is resolved to greater detail in the inset photograph showing nuclei of infected hepatocytes. NS normal (non-immune) serum. $A S$ antiserum 

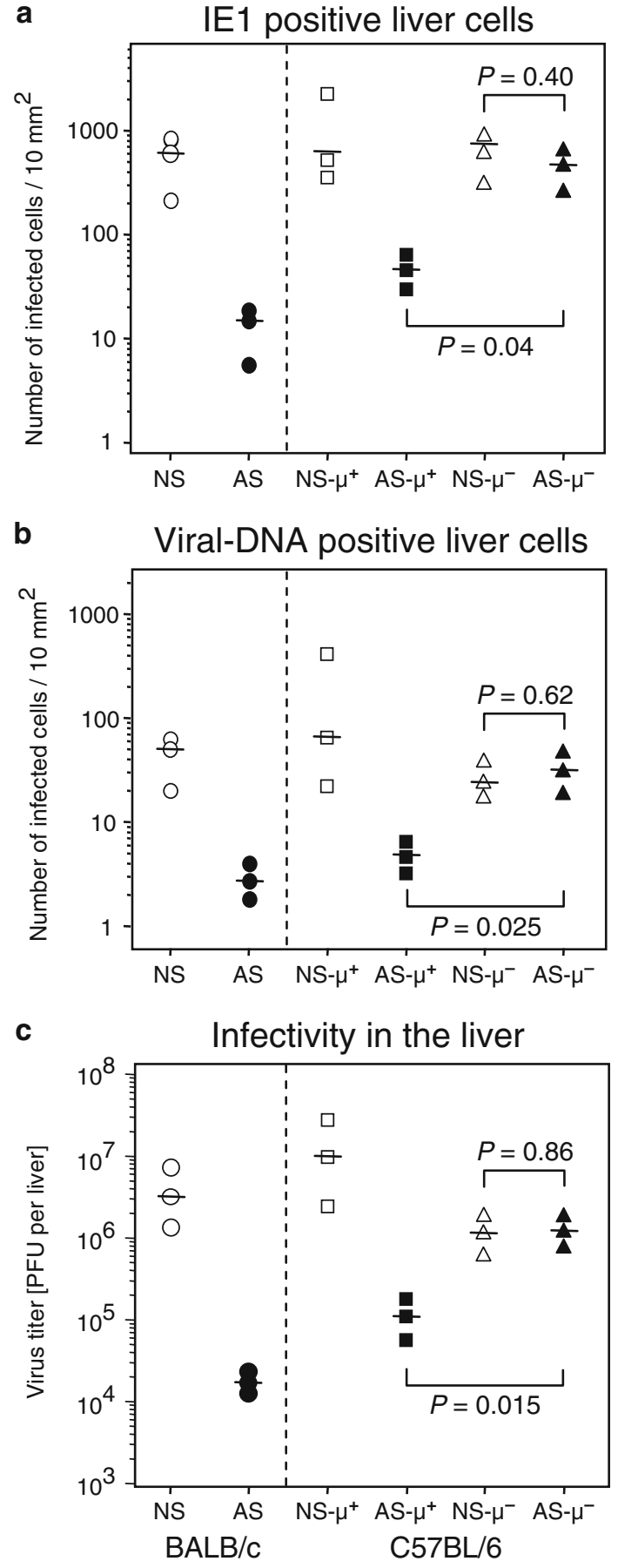

Klenovsek et al. [14], our present data document that antibodies are very efficient in controlling acute mCMV infection. Here we have added the information that antibodies not only inhibit long-distance primary dissemination from a portal of entry to target tissues as well as a secondary seeding but also protect from the focal cell-to-cell spread of virus after tissue infection is established. This is the quality that is relevant for preventing local histopathology and dysfunction.
Fig. 5 Protective antiviral activity of donor sera in the liver of recipients a Quantitation of infected liver cells (mostly hepatocytes) on the basis of intranuclear IE1 protein detected by immunohistological staining (see also Fig. 4 with methods published in [20]). This represents cells in all phases of infection. b Quantitation of infected liver cells on the basis of intranuclear inclusion bodies (sites of viral DNA packaging into nucleocapsids) detected by in situ hybridization [20]. This represents cells in the late phase of infection. c Quantitation of infectivity in the liver by the virus plaque forming unit (PFU) assay [20]. This represents viral productivity. All data refer to day 10 after infection, that is 4 days after serum transfer (see schema in Fig. 2). The quantitation of infected cells was performed for a representative tissue section area of $10 \mathrm{~mm}^{2}$, which is 100 -fold the area shown in the photographs in Fig. 4. Symbols represent the different sera as defined in Fig. 3. $P$ values for significance are shown for group comparisons of particular interest (unpaired $t$-test, two-sided; http://www.graphpad.com/quickcalcs/ttest1.cfm). Data from two independent experimental groups are considered to be significantly different if $P<0.05$

Recent work by Sacher et al. [23] has opened new possibilities for studying virus dissemination and spread using cell-type specific recombination of a floxed green fluorescent protein reporter virus in mice that express Cre recombinase under the control of cell-type specific promoters (see also the contribution by Sacher et al. in this issue of MMI). Tracing virus recombined in hepatocytes of Alb-Cre mice has led to the astounding finding that virus produced in hepatocytes does not contribute to virus dissemination to other organs by secondary viremia, a finding that challenges a dogma in virology. The virus confinement to the liver, however, did not appear to be a function of antiviral antibodies.

Primary dissemination from the portal of entry is thought to occur not by free virions but by infected cells of the myeloid lineage [24] (for a review, see [25]), a conclusion that is further supported by the finding that deletion of the antiapoptotic mCMV gene M36 prevents virus dissemination [26-28]. It is currently open to question at which stage in primary dissemination antibodies operate, and in particular, if the cell-bound transit through the vascular compartment is protected from antibodies. Antibodies might rather neutralize cell-free virions before uptake by the "vehicle cells" and/or their release at the target sites. Our, here reported finding that the priming of CD8 T cells specific for non-virion epitopes is blocked argues for a neutralization of free virions prior to infection of local cells and protein uptake by antigen-presenting cells, by dendritic cells in particular.

It is also unclear how antibodies prevent the cell-to-cell spread after established infection of liver tissue. Clearly, if the infection is transmitted between cells not by direct cellto-cell contact but by a cell-to-interstitium-to-cell route, progeny virions would become accessible to antibodies. Such a mechanism is actually suggested by the dimension and globular shape of advanced infectious foci (recall Fig. 4), as the microanatomy of the liver parenchyma would 
rather predict a longitudinal shape of infectious foci in the event of direct cell-to-cell spread.

It should be noted that alternative effector mechanisms of antibody-mediated antiviral control, such as antibodydependent cellular cytotoxicity (ADCC) are likely to be suppressed in the model of the immunocompromised host studied here. The correlation between protection in vivo and the titer of neutralizing antibodies indeed argues against a significant contribution of non-neutralizing antibodies that might operate by means of ADCC.

Whatever the mechanism may be, the data suggest that adoptive transfer of CMV-specific antibodies and/or memory B cells is a therapeutic option.

Acknowledgments We greatly appreciate the help by Stipan Jonjić (Department of Histology and Embryology, Faculty of Medicine, University of Rijeka, Croatia) who generously supplied us with immune sera and monoclonal antibodies. This work is part of the MD thesis of the first author N.W. Support was provided by the Deutsche Forschungsgemeinschaft, SFB 490, individual projects E2 (C.O.S. and M.J.R.), E4 (M.J.R.) and E3 (R.H. and S.I.S.), SFB 432, individual project A10 (J.P.) and Clinical Research Group KFO 183, individual project TP8 "Establishment of a challenge model to optimize the immunotherapy of cytomegalovirus diseases" (M.J.R. and N.A.W.L). Special thanks go to the "Dr. Gerhard und Martha Röttger-Stiftung" for a generous donation.

\section{References}

1. Mach M (2006) Antibody-mediated neutralization of infectivity. In: Reddehase MJ (ed) Cytomegaloviruses: molecular biology and immunology. Caister Academic Press, Norfolk, pp 265-283

2. Pepperl-Klindworth S, Plachter B (2006) Current perspectives in vaccine development. In: Reddehase MJ (ed) Cytomegaloviruses: molecular biology and immunology. Caister Academic Press, Norfolk, pp 551-572

3. Britt WJ (1996) Vaccines against human cytomegalovirus: time to test. Trends Microbiol 4:34-38

4. Gonczol E, Plotkin S (2001) Development of a cytomegalovirus vaccine: lessons from recent clinical trials. Expert Opin Biol Ther $1: 401-412$

5. Arvin AM, Fast P, Myers M, Plotkin S, Rabinovich R; National Vaccine Advisory Committee (2004) Vaccine development to prevent cytomegalovirus disease: report from the national vaccine advisory committee. Clin Infect Dis 39:233-239

6. Emery VC (1998) Relative importance of cytomegalovirus load as a risk factor for cytomegalovirus disease in the immunocompromised host. In: Scholz M, Rabenau HF, Doerr HW, Cinatl J Jr (eds) Monographs in virology, vol 21: CMV-related immunopathology. Karger, Basel, pp 288-301

7. Araullo-Cruz TP, Ho M, Armstrong JA (1978) Protective effect of early serum from mice after cytomegalovirus infection. Infect Immun 21:840-842

8. Shanley JD, Jordan MC, Stevens JG (1981) Modification by adoptive humoral immunity of murine cytomegalovirus infection. J Infect Dis 143:231-237

9. Gorman S, Harvey NL, Moro D, Lloyd ML, Voigt V, Smith LM, Lawson MA, Shellam GR (2006) Mixed infection with multiple strains of murine cytomegalovirus occurs following simultaneous or sequential infection of immunocompetent mice. J Gen Virol 87:1123-1132
10. Dix RD, Cray C, Cousins SW (1987) Antibody alone does not prevent experimental cytomegalovirus retinitis in mice with retrovirus-induced immunodeficiency (MAIDS). Ophthalmic Res 29:381-392

11. Kitamura D, Roes J, Kühn R, Rajewsky K (1991) A B cell-deficient mouse by targeted disruption of the membrane exon of the immunoglobulin mu chain gene. Nature 350:423-426

12. Reddehase MJ, Balthesen M, Rapp M, Jonjić S, Pavić I, Koszinowski UH (1994) The conditions of primary infection define the load of latent viral genome in organs and the risk of recurrent cytomegalovirus disease. J Exp Med 179:185-193

13. Jonjić S, Pavić I, Polić B, Crnković I, Lucin P, Koszinowski UH (1994) Antibodies are not essential for the resolution of primary cytomegalovirus infection but limit dissemination of recurrent virus. J Exp Med 179:1713-1717

14. Klenovsek K, Weisel F, Schneider A, Appelt U, Jonjić S, Messerle M, Bradel-Tretheway B, Winkler TH, Mach M (2007) Protection from CMV infection in immunodeficient hosts by adoptive transfer of memory B cells. Blood 110:3472-3479

15. Reddehase MJ (2002) Antigens and immunoevasins: opponents in cytomegalovirus immune surveillance. Nat Rev Immunol 2:831844

16. Holtappels R, Munks WM, Podlech J, Reddehase MJ (2006) CD8 T-cell-based immunotherapy of cytomegalovirus disease in the mouse model of the immunocompromised bone marrow transplantation recipient. In: Reddehase MJ (ed) Cytomegaloviruses: molecular biology and immunology. Caister Academic Press, Norfolk, pp 383-418

17. Streblow DN, Varnum SM, Smith RD, Nelson JA (2006) A proteomics analysis of human cytomegalovirus particles. In: Reddehase MJ (ed) Cytomegaloviruses: molecular biology and immunology. Caister Academic Press, Norfolk, pp 91-110

18. Holtappels R, Thomas D, Podlech J, Reddehase MJ (2002) Two antigenic peptides from genes $\mathrm{m} 123$ and $\mathrm{m} 164$ of murine cytomegalovirus quantitatively dominate CD8 T-cell memory in the H-2d haplotype. J Virol 76:151-164

19. Erlach KC, Böhm V, Seckert CK, Reddehase MJ, Podlech J (2006) Lymphoma cell apoptosis in the liver induced by distant murine cytomegalovirus infection. J Virol 80:4801-4819

20. Podlech J, Holtappels R, Grzimek NKA, Reddehase MJ (2002) Animal models: murine cytomegalovirus. In: Kaufmann SHE, Kabelitz D (eds) Methods in microbiology 32. Immunology of infection. Academic Press, San Diego, pp 493-525

21. Simon CO, Holtappels R, Tervo HM, Böhm V, Däubner T, Oehrlein-Karpi SA, Kühnapfel B, Renzaho A, Strand D, Podlech J, Reddehase MJ, Grzimek NK (2006) CD8 T cells control cytomegalovirus latency by epitope-specific sensing of transcriptional reactivation. J Virol 80:10436-10456

22. Podlech J, Holtappels R, Wirtz N, Steffens HP, Reddehase MJ (1998) Reconstitution of CD8 T cells is essential for the prevention of multiple-organ cytomegalovirus histopathology after bone marrow transplantation. J Gen Virol 79:2099-2104

23. Sacher T, Podlech J, Mohr AC, Jordan S, Ruzsics Z, Reddehase MJ, Koszinowski UH (2008) The major virus producing cell type during murine cytomegalovirus infection, the hepatocyte, is not the source of virus dissemination in the host. Cell Host Microbe (in press)

24. Noda S, Aguirre SA, Bitmansour A, Brown JM, Sparer TE, Huang J, Mocarski ES (2006) Cytomegalovirus MCK-2 controls mobilization and recruitment of myeloid progenitor cells to facilitate dissemination. Blood 107:30-38

25. Mocarski ES, Hahn G, White KL, Xu J, Slobedman B, Hertel L, Aguirre SA, Noda S (2006) Myeloid cell recruitment and function in pathogenesis and latency. In: Reddehase MJ (ed) Cytomegaloviruses: molecular biology and immunology. Caister Academic Press, Norfolk, pp 465-481 
26. Ménard C, Wagner M, Ruzsics Z, Holak K, Brune W, Campbell AE, Koszinowski UH (2003) Role of murine cytomegalovirus US22 gene family members in replication in macrophages. J Virol 77:5557-5570

27. Cičin-Sain L, Podlech J, Messerle M, Reddehase MJ, Koszinowski UH (2005) Frequent coinfection of cells explains functional in vivo complementation between cytomegalovirus variants in the multiply infected host. J Virol 79:9492-9502

28. Čičin-Sain L, Ruzsics Z, Podlech J, Bubić I, Ménard C, Jonjić S, Reddehase MJ, Koszinowski UH (2008) Dominant-negative FADD rescues the in vivo fitness of a cytomegalovirus lacking an anti-apoptotic viral gene. J Virol 82:2056-2064 